\title{
Outcomes-Based Contracting Experience: Research Findings from U.S. and European Stakeholders
}

\author{
Tara Nazareth, MPH; John J. Ko, PharmD, MS; Rahul Sasane, PhD; Christian Frois, PhD; \\ Stephen Carpenter, MBA; Sebastian Demean, BA; Ashok Vegesna, PharmD, RPh; Eric Wu, PhD; \\ and Robert P. Navarro, PharmD
}

\begin{abstract}
BACKGROUND: Outcomes-based contracts (OBCs), a type of risk-sharing arrangement (RSA), have emerged as a promising avenue for payers to engage with pharmaceutical manufacturers to share risk and improve patient access to medicines via evaluation of real-world outcomes.

OBJECTIVE: To assess the level of recent $\mathrm{OBC}$ activity and stakeholder perceptions of these arrangements, as well as the outlook for future $\mathrm{OBC}$ activity from a payer and manufacturer perspective in the United States and EU-5 (France, Germany, Italy, Spain, and the United Kingdom).

METHODS: Using a structured questionnaire, interviews were conducted with 27 experts, including 14 U.S. payers, 5 EU-5 national payers, and 8 manufacturer pricing/market access executives (4 U.S., 4 EU-5). We also used the University of Washington's Performance Based Risk-Sharing (PBRS) database and other targeted publicly available information.
\end{abstract}

RESULTS: Publicly disclosed information on OBCs understates the level of $\mathrm{OBC}$ activity, since many arrangements are confidential. Overall, U.S. and EU-5 interviewees generally expected that 2 to 3 times more OBCs would be implemented in the next 5 years than in the previous 5 years. Key drivers included the introduction of a national OBC framework in Spain, potentially a similar framework in the United Kingdom, a growing sickness fund activity in Germany, and a U.S. movement towards accountable care. Motivation for OBCs varied markedly across markets and stakeholders, with operational feasibility noted as a significant hurdle in the United States and France. Along with improving health outcomes, cost and financial risk reduction were the primary $\mathrm{OBC}$ motivators for payers, while potential access or reimbursement gains were key factors for manufacturers.

CONCLUSIONS: Using direct input from U.S. and EU-5 payer and pharmaceutical manufacturer decision makers, this research suggests that high $\mathrm{OBC}$ growth is expected in the EU-5 and, to a more moderate extent, in the United States, particularly if clear, simpler OBC frameworks can be developed.

J Manag Care Spec Pharm. 2017;23(10):1018-26

Copyright $\odot 2017$, Academy of Managed Care Pharmacy. All rights reserved.

\section{What is already known about this subject}

There is growing interest in outcomes-based contracts (OBCs) among manufacturers and payers including in areas of rare/ orphan diseases and oncology.

Significant challenges in OBC operationalization and implementation exist, given the potential complexity involved with these agreements.

Because OBC contracting activity is largely confidential and unpublicized, the level of activity and trends are unclear.

\section{What this study adds}

This study captured EU-5 (France, Germany, Italy, Spain, and the United Kingdom) and U.S. OBC historical activity and trends beyond limited publicized activity.

Nearly all payers and pharmaceutical manufacturers reported that OBCs offer positive value to their organizations.

OBCs are increasingly becoming established and growing options for certain therapies in the EU-5 and the United States, with 2-3 times more OBCs expected to be implemented in the next 5 years.

B udgetary pressures, rising health care costs, value assessments, alternative payment and reimbursement models, and health care standards and reforms are increasingly motivating health care payers to share risk and increase the efficiency of care. In Europe, the fiscal crisis has led payers to significantly limit access to new, high-cost medicines. ${ }^{1,2}$ In the United States, there are mounting pressures to decrease overall health care spending and increase stakeholder accountability. ${ }^{3,4}$ For example, the U.S. Department of Health and Human Services has set a goal of $90 \%$ of Medicare payments to be tied to value by $2018 .{ }^{5}$ Generally, there is an increasing need for novel approaches to enable access to medicines that can have a demonstrable effect on patient outcomes. ${ }^{6-12}$

Outcomes-based contracts (OBCs), a type of risk-sharing arrangement (RSA), have emerged as a promising avenue for payers to engage with manufacturers in linking value-based payments (i.e., reimbursement and rebates) with real-world outcomes. ${ }^{13-16}$ In the United States, several recent RSAs have received considerable media exposure. For example, in 2016, Cigna signed 2 RSAs with the manufacturers of the proprotein convertase substilisin/kexin type 9 (PCSK9) inhibitors (Repatha and Praluent) for hypercholesterolemia. United Healthcare also reached an agreement with Gilead for Harvoni, a breakthrough hepatitis C treatment, in 2015. Despite this recent increase in public reporting, details of contracts between manufacturers and payers are largely not disclosed. ${ }^{17,18}$ This lack of transparency regarding $O B C$ activity and results has created ambiguity about whether OBCs have been a passing trend or are a rising reality and has prevented knowledge of past OBCs from being used by other manufacturers and payers. ${ }^{19,20}$ 


\begin{tabular}{|c|c|}
\hline Research Sample Overview & Participant Profile \\
\hline 14 U.S. payers & $\begin{array}{l}\text { - } 10 \text { pharmacy and medical directors from national/regional commercial and Medicare Part D plans } \\
\text { - } 2 \text { leaders of accountable care organizations } \\
\text { - } 2 \text { advisors for the Centers for Medicare \& Medicaid Services }\end{array}$ \\
\hline $\begin{array}{l}5 \text { EU-5 national payer } \\
\text { advisors }\end{array}$ & $\begin{array}{l}\text { - Advisor, Economic Committee for Healthcare Products (CEPS), France } \\
\text { - Representative/advisor, large sickness fund, Germany } \\
\text { - Advisor from the Italian Medicines Agency (AIFA), Italy } \\
\text { - Advisor, Interministerial Commission for Medicine Prices (CIPM), Spain } \\
\text { - Advisor, Department of Health Services and National Institute for Health and Care Excellence (NICE), United Kingdom }\end{array}$ \\
\hline $\begin{array}{l}8 \text { pharmaceutical } \\
\text { manufacturer experts }\end{array}$ & $\begin{array}{l}\text { - } 4 \text { EU-5 pricing/market access executives } \\
\text { - } 4 \text { U.S. pricing/market access executives }\end{array}$ \\
\hline
\end{tabular}

Although important initial research has been done to understand OBCs, insights from previous research are often based on limited publicly available information. Carlson et al. (2014) and Garrison et al. (2014) reported that the pace of OBC activity has slowed. ${ }^{14,21}$ Garrison et al. (2015) relied on a review of the published literature for their estimates of the volume of RSAs.22 Ferrario and Kanavos (2013) provide a unique review of OBC-related activity in European countries ${ }^{23}$; however, their research provides limited information on the trends, perceptions, and outlook for OBCs, and no information is presented for the United States. Although there is evidence that OBC implementation has not been without challenges, ${ }^{20,23,24}$ insights from past implementations are obscured by the lack of public information on these arrangements.

The objective of this study was to assess the level of recent $\mathrm{OBC}$ activity and stakeholder perceptions of these arrangements, as well as the outlook for future OBC activity from a payer and manufacturer perspective in the United States and EU-5 (France, Germany, Italy, Spain, and the United Kingdom).

\section{Methods}

To perform our research, we combined structured interviews with a targeted literature review of publicly available information on specific OBCs in order to provide an assessment of the past and future volume of OBC activity for the United States and the EU-5.

\section{Interview Participant Profile Details}

From November 2014 to January 2015, we conducted telephone interviews with 27 senior experts from the United States and the EU-5, including 14 U.S. payers, 5 EU-5 national payer advisors, and 8 pharmaceutical manufacturer pricing and market access executives (Table 1). These research participants were screened based on their role and experience in pricing, contracting, and reimbursement decision making within targeted organizations.

For the United States, targeted payer organizations included 10 large national and regional commercial and Medicare Part D payers, the Centers for Medicare \& Medicaid Services (CMS), and 2 accountable care organizations (ACOs). For the EU-5, bodies with national responsibility for manufacturer contracting decisions were targeted. For manufacturers, participants were recruited from the top 20 global pharmaceutical companies. Potential participants were identified by the authors of this study who were not affiliated with the study sponsor, leveraging their network of contacts at targeted payer and pharmaceutical organizations. The target U.S. payer sample size was determined based on the need to capture the view of most U.S. national commercial payers, CMS, and a few large regional payers and ACOs.

The EU-5 payer sample size was made up of 1 participant from each country, with the assumption that 1 participant was enough to capture OBC levels of activity and experience in each country. The pharmaceutical manufacturer sample size was established to provide an appropriate representation of the diversity within the top 20 global pharmaceutical companies. The targeted sample sizes were achieved as planned.

Interview Approach. One-hour interviews were conducted by experienced interviewers using a structured questionnaire and WebEx teleconference software. The identities of the study sponsor and respondents were not disclosed to each another, and no raw data nor individual- or organization-level results were shared between parties. To avoid any conflict of interest, and to ensure the anonymity of the participants, all study data were collected, analyzed, and pooled by the subset of authors unaffiliated with the study sponsor, and participants were guaranteed that no identifying characteristics about them or that of their organizations would be shared with the sponsor or third parties because of the sensitive nature of contracting information.

Data collected from the interviews included historical OBC activity (e.g., the number and goals of OBCs implemented in the past 5 years in the interviewees' respective organizations at the time of the interview, extent of public disclosure of past OBC activity, and primary outcomes used in OBCs); OBC perceptions (e.g., OBC implementation challenges/barriers and $\mathrm{OBC}$ value for participants and their organizations); and future 


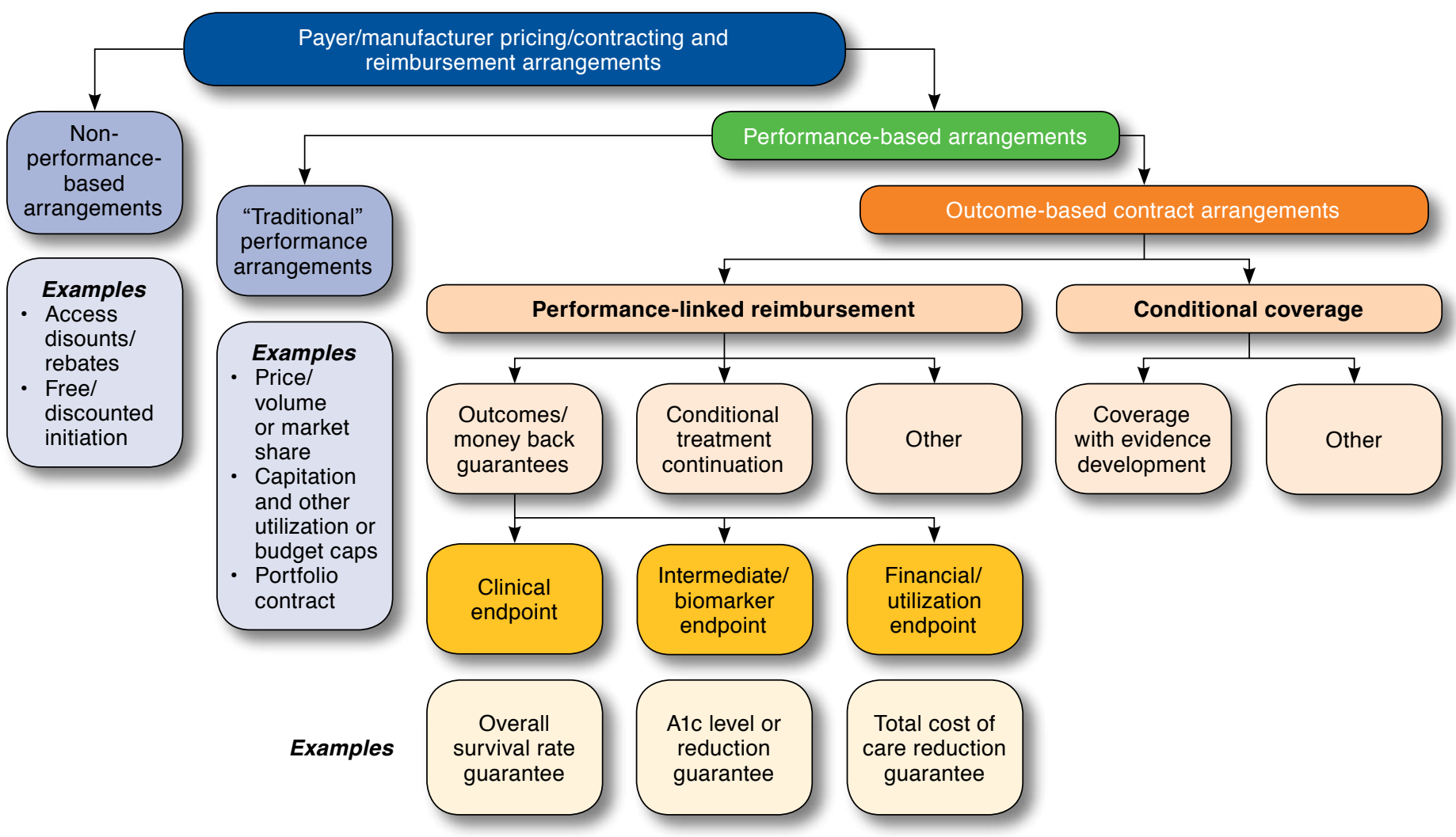

Adapted from Carlson J, Sullivan S, Garrison L, Neumann P, Veenstra D. Linking payment to health outcomes: a taxonomy and examination of performance-based reimbursement schemes between healthcare payers and manufacturers. 32

Alc $=$ hemoglobin Alc.

OBC activity (e.g., anticipated volume and focus and priorities of OBCs in the 5 years from the time of the interviews).

For questions with quantitative answers, averages and range across participants were reported. No institutional review board approval was sought, since this research did not involve human subjects.

\section{Targeted Literature Review of Publicized OBCs}

To complement the interview research, we also performed a targeted literature review of publicly available information on specific OBCs for the countries of interest (the United States and the EU-5), limiting relevant data extraction to OBCs for pharmaceutical products. The literature search included data from the University of Washington's Performance Based Risk Sharing (PBRS) database, ${ }^{25}$ which was complemented by additional information on $\mathrm{OBC}$ arrangements available in the public domain.
Data sources searched to complement the PBRS database and increase its coverage of publicly disclosed OBCs included payer and health technology assessment agency websites, Factiva, PubMed, and recent congress abstracts (Academy of Managed Care Pharmacy and International Society for Pharmacoeconomics and Outcomes Research). Keywords used included outcome-based contract and risk-sharing contract, along with their local language translation for the EU-5 countries. In particular, a list of recent public arrangements during 20122014, negotiated by the Italian Medicines Agency (AIFA), was obtained, and the corresponding details were added to our publicized $\mathrm{OBC}$ data extract. Based on our experience, much of the publicly disclosed OBCs are identified in press releases or data releases by payer organizations (rather than in scientific literature), so the literature review was primarily intended to ensure that OBC activity disclosed on national U.S. and EU-5 payer websites was captured in this review. Thus, the review was targeted and not intended to be systematic. 
TABLE 2 U.S. and EU-5 OBC Landscape Overview

\begin{tabular}{|c|c|c|c|c|}
\hline Country & $\begin{array}{c}\text { OBCs per } \\
\text { Participant } \\
\text { (Past } 5 \text { Years) } \\
\end{array}$ & $\begin{array}{c}\text { OBCs per } \\
\text { Participant } \\
\text { (Next } 5 \text { Years) } \\
\end{array}$ & OBC Participant Focus & Comments \\
\hline \multicolumn{5}{|c|}{ Payer participant perspective } \\
\hline United States & $\begin{array}{c}\sim 3 \\
(0-4 \text { range })\end{array}$ & $\begin{array}{c}\sim 7 \\
(1-20 \text { range })\end{array}$ & $\begin{array}{l}\text { - Commercial and Medicare Part D } \\
\text { plans }\end{array}$ & - No CMS activity \\
\hline Italy & $\sim 50$ & $60-70$ & $\begin{array}{l}\text { - National focus (AIFA) } \\
\text { - Focus on new/high-cost oncology } \\
\text { products (response-based } \\
\text { arrangements) }\end{array}$ & $\begin{array}{l}\text { - Accounts for majority of } \mathrm{OBC} \text { activity at the national } \\
\text { level within EU-5 }\end{array}$ \\
\hline Spain & $5-8$ & $\sim 50$ & - National focus (CIPM) & $\begin{array}{l}\text { - New OBC framework/legislation introduced: no } \\
\text { national level OBC activity before } 1.5 \text { years ago } \\
\text { - Significant activity following implementation of } \\
\text { national OBC framework (primary focus on response- } \\
\text { based arrangements) }\end{array}$ \\
\hline Germany & $\sim 50$ & $60-70$ & - Sickness fund focus & $\begin{array}{l}\text { - No OBC activity at the national/federal level } \\
\text { - High level of activity appears to be occurring at the } \\
\text { sickness fund level } \\
\text { - Focus on mature/high total budget items }\end{array}$ \\
\hline United Kingdom & $5-6$ & $20-40$ & - National focus (DH/NICE) & $\begin{array}{l}\text { - Lull after historically higher } \mathrm{OBC} \text { activity } \\
\text { - Significant increase expected, perticularly around } \\
\text { new/high-cost products, once new scheme framework } \\
\text { implemented/finalized }\end{array}$ \\
\hline France & 5 & 10 & - National focus (CEPS) & $\begin{array}{l}\text { - New OBC framework/legislation introduced in } 2013 \\
\text { - Focus on new drugs for which benefits can only be } \\
\text { fully demonstrated with real-world evidence }\end{array}$ \\
\hline \multicolumn{5}{|c|}{ Manfacturer participant perspective } \\
\hline United States & $\begin{array}{c}\sim 1 \\
(0-3 \text { range }) \\
\end{array}$ & $\begin{array}{c}\sim 10 \\
(1-20 \text { range })\end{array}$ & \multicolumn{2}{|c|}{$\begin{array}{l}\text { - Limited OBC activity to date as manufacturers mostly motivated by "getting their feet wet" } \\
\text { - Significant growth expected by some in order to partake in new business models (e.g., ACOs) }\end{array}$} \\
\hline$\overline{\mathrm{EU}-5}$ & $\begin{array}{c}\sim 13 \\
(3-30 \text { range })\end{array}$ & $\begin{array}{c}\sim 20 \\
(7-25 \text { range })\end{array}$ & \multicolumn{2}{|c|}{$\begin{array}{l}\text { - National focus of OBCs appears to be primarily on new products/indications while } \\
\text { "sub-national" focus on mature high-budget items; local/regional contracting appears } \\
\text { to be limited for most manufacturers. } \\
\text { - Expected increase in OBC activity driven by new country OBC framework introduction (e.g., } \\
\text { Spain) and increasing budget pressures. High level of OBC activity driven by Italy. }\end{array}$} \\
\hline \multicolumn{5}{|c|}{$\begin{array}{l}\text { Note: Information in this table is from interviews with stakeholders for this study. } \\
\text { ACO=accountable care organization; AIFA=Agenzia Italiana del farmaco (Italian Medicines Agency); CEPS=Comité Economique des Produits de Santé (Economic com- } \\
\text { mittee for health products); CIPM =Comisión Interministerial de Precios de los Medicamentos (Interministerial Drug Pricing Commission); CMS=Centers for Medicare E } \\
\text { Medicaid Services; DH = Department of Health; EU-5= France, Germany, Italy, Spain, and the United Kingdom; NICE= National Institute for Health and Care Excellence; } \\
\text { OBC=outcomes-based contract. }\end{array}$} \\
\hline
\end{tabular}

OBC Taxonomy Used. We used an OBC definition adapted from Carlson et al. (2010) to provide a consistent taxonomy for the primary research with U.S. and EU-5 stakeholders and the literature review (Figure 1). ${ }^{26}$ For the purposes of this research, an $\mathrm{OBC}$ was a scheme between a health care payer and a drug manufacturer in which the price, level or nature of reimbursement, or payer coverage of a drug is tied to 1 or more future clinical or other health outcome measures. Two types of OBCs were a priori distinguished: (1) performance-linked reimbursement arrangements, where the reimbursement level of the drug is linked to the measure of clinical outcomes, and (2) conditional coverage arrangements, where coverage is granted conditionally on the initiation of a program of data collection that informs the use of the drug in the payer population.
Key adjustments to the Carlson et al. taxonomy included (a) the explicit inclusion of financial/utilization endpoints (i.e., relevant outcomes were assumed to include not just clinical and intermediate endpoints) such as total cost of care or hospitalizations (important outcomes of interest to payers); (b) clarification of what traditional and non-OBC arrangements cover, based on taxonomy more familiar to payer and manufacturer experts (e.g., access discount/rebates, price/volume or price/market share-based, and portfolio arrangements); and (c) use of the adapted OBC definition previously mentioned. The adjustments were primarily made to make it easier for payer and manufacturer experts unfamiliar with the Carlson et al. work to understand the taxonomy. 


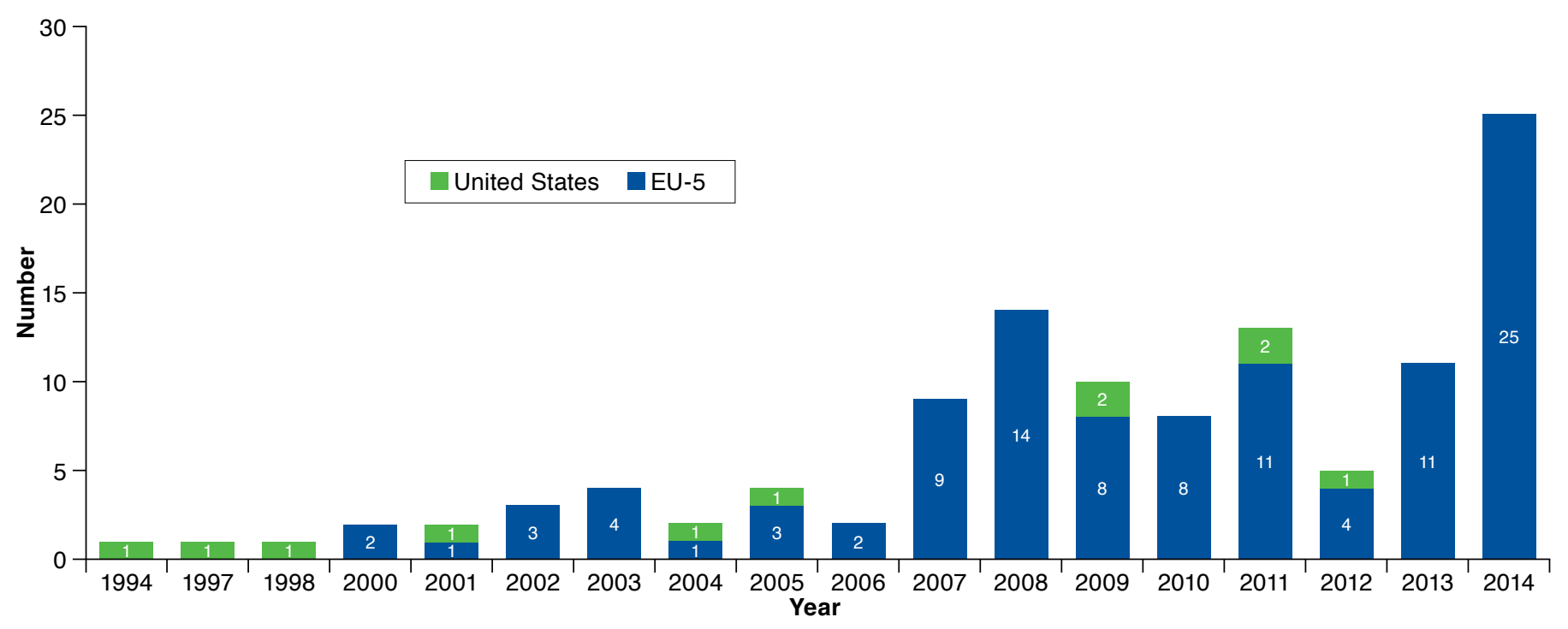

EU-5 = France, Germany, Italy, Spain, and the United Kingdom; OBC= outcomes-based contract.

\section{Results}

$\overline{\text { All research participants had some familiarity with OBCs and }}$ had previously considered their business relevance. However, the level of $\mathrm{OBC}$ experience varied across participants and countries. Unless otherwise noted, the results in this section are solely based on comments from interview participants.

\section{Historical OBC Activity}

Level of Historical OBC Activity. As shown in Table 2, our primary research found that significant levels of $\mathrm{OBC}$ activity have occurred in the past 5 years (approximately 2010-2014). The level of activity was found to vary across countries. With approximately 10 OBCs per year implemented over the last 5 years, Italy was at the forefront of OBC activity at the national level, closely followed by Spain and Germany. The United States has been increasingly following suit, with several individual participants reporting up to 4 OBCs implemented over the last 5 years.

The United Kingdom and CMS in the United States are 2 notable exceptions in terms of OBC activity. In the United Kingdom, after 5-6 OBCs were implemented in the early 2010s, no additional OBC activity was reported through 2015. Successive rounds of health care reform have delayed the development of a new OBC framework (intended to address some of the issues encountered in past OBCs). In the United States, manufacturers, payers, and CMS are expressing greater interest in new contracting models. For example, CMS has been an early proponent of programs aimed at determining coverage for new health technologies through coverage with evidence development. CMS has expressed interest in exploring performance- or value-based payment for pharmaceuticals.

Level of Historical OBC Activity Versus Publicly Disclosed Data. The literature review identified 106 publicized OBCs in the EU-5 and 11 in the United States from 1994 to 2014, of which 60 in the EU-5 and 3 in the U.S. were announced in the last 5 years (2010-2014). As Figure 2 shows, the number of publicized OBCs has increased over time. Europe has historically led publicized $\mathrm{OBC}$ activity, with Italy implementing more than two thirds of publicly disclosed OBCs. Over 60\% of the publicized OBCs were in oncology, with the remaining activity in neurology, ophthalmology, endocrinology, and other therapeutic areas.

The publicly available literature appears to greatly understate the actual level of OBC activity when compared with the activity reported by the interview participants in the past 5 years. For example, in the United States, while the targeted literature review identified only $3 \mathrm{OBC}$ drug schemes in the past 5 years, some interviewed stakeholders reported enacting up to $4 \mathrm{OBCs}$ over the same period (i.e., each of these research participants reported more than the total reported in the literature). Furthermore, even those U.S. stakeholders with more limited OBC activity mentioned that they had frequently negotiated or considered implementing such arrangements. The same is true for Spain, where the introduction of a new national OBC framework has recently facilitated the implementation of about 5-8 OBCs after no OBC activity at the national level before 2013), yet little of that activity has been publicized. 


\section{A. Value for Payers}

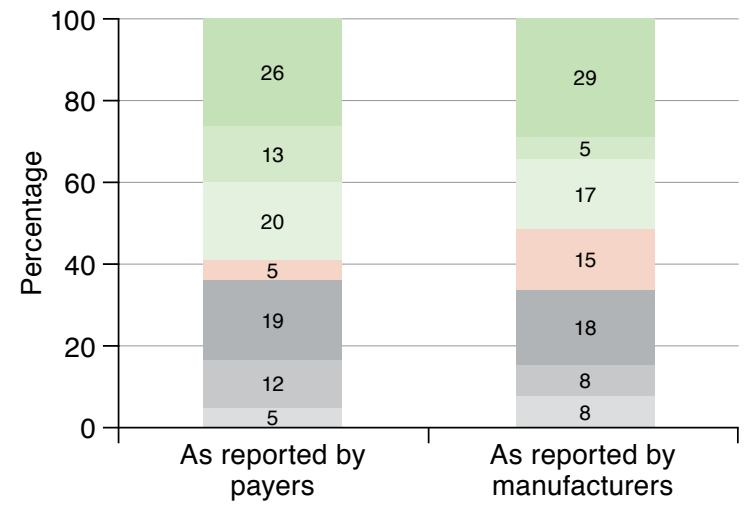

\section{Reduce costs}

Increase pharmacy discount/rebate level

Reduce financial risks

Provide faster access to innovative medicines

Improve patient outcomes

Internal or external goal

Avoid providing access to an overly broad patient population

\section{B. Value for Manufacturers}

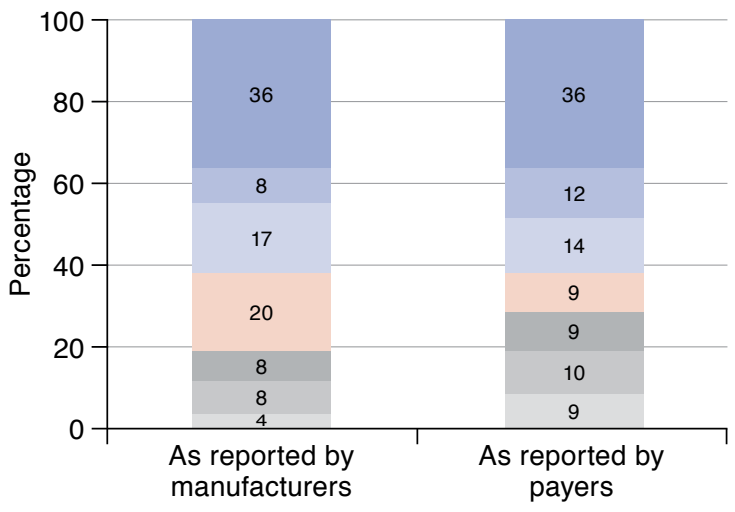

Improve level of access

Improve reimbursement

Increrase revenue (gross/net)

Reduce uncertainty for payers when long-term benefits are uncertain

Reduce discount/rebate pressure

Gain a competitive advantage

Internal or external goal

Note: Internal goal was defined as demonstrating value to participant's company/organization management (e.g., if increasing OBCs is a corporate objective), while external goal was defined as demonstrating value to society (for EU-5 participants) or members/customers (for U.S. participants).

EU-5= France, Germany, Italy, Spain, and the United Kingdom; OBC= outcomes-based contract.

Similarly, all but one of the recent OBCs of our German sickness fund research participants have remained confidential.

Focus and Motivation of Historical OBC Activity. Based on the interviews, the focus of implemented OBCs across studied countries appears to have been driven by different priorities of national and subnational payers (e.g., U.S. regional managed care organizations and German sickness funds). Past OBC activity by national payers has primarily focused on new drugs (or indications) and high cost per patient products (estimated $\geq 95 \%$ of total activity), while OBC activity by subnational payers has been more focused on mature products (estimated $\geq 75 \%$ of total activity) and, in particular, high-budget items (e.g., anti-tumor necrosis factor agents). All stakeholders who implemented OBCs reported response to therapy (e.g., based on patient disease improvement/stabilization endpoints relevant to the particular therapeutic area) as the most frequently used primary conditioning outcome, but other outcomes were reported to be involved as well (e.g., adherence and resource or financial utilization).

OBCs were primarily motivated by the desire of stakeholders to assess or convey the value of a drug, particularly in an environment increasingly pressured by limited budgets, rising costs, and significant change. U.S. health plans also pursued OBCs as an opportunity to share risk with manufacturers, particularly when they were already accountable for the outcomes of interest (e.g., goals set by Healthcare Effectiveness Data and Information Set [HEDIS] or CMS star ratings). In addition to enacting OBCs as a means of real-world value demonstration to gain, improve, or maintain access, manufacturers have historically pursued OBCs to focus product discussions with payers on value and differentiation (as opposed to solely cost), foster better relationships with payers, fit within a particular payer's pricing and reimbursement framework (e.g., for oncology products in Italy), and/or when an innovative strategy is needed. Payer and manufacturer stakeholders who were interviewed had also implemented OBCs in order to gain experience with novel contracting approaches, prepare for evolving models such as the U.S. ACOs, and showcase value to customers (e.g., employers for payers).

OBC Implementation Experience. OBC implementation has not been without challenges. Most notably, the absence of an effective guiding framework to generate, implement, coordinate, and monitor OBCs was noted by many interviewed stakeholders as an important constraint to OBC activity. By 
framework, participants generally indicated an approach to OBCs that establishes key parameters or building blocks for payers and manufacturers to negotiate OBCs.

In addition, there are operational constraints to engaging in OBCs, as previously reported. ${ }^{20,22} \mathrm{OBC}$ implementation has historically been hindered by a series of factors, including the availability, consistency, and reliability of patient data; selection of appropriate conditioning outcomes; and alignment of data needs and expectations between partners. Early and sustained involvement of health economics and outcomes research in the OBC design and implementation stages was considered important by several manufacturers and payers. U.S. study participants cited the need to work within the confines of relevant regulatory requirements (e.g., Medicaid Best Price, AntiKickback statute/laws, and False Claims Act considerations).

Notwithstanding the upfront investment required to get OBCs started (e.g., in terms of negotiation and outcome data infrastructure), payers who have implemented OBCs noted that the arrangements have been generally successful at reducing patient costs and budget uncertainty (e.g., by reducing the costs associated with nonresponders, mitigating uncertainty related to product performance, and/or increasing pharmacy discount/ rebate levels). Similarly, manufacturers noted that OBCs helped with access for their drugs, especially in situations when the incremental value proposition of the product was unclear.

\section{Value of OBCs for Payers and Manufacturers}

Nearly all payer and manufacturer stakeholders who were interviewed reported that OBCs offered positive value to their organizations, countries, or shareholders, with both partners benefiting from the arrangements. In addition, payers generally perceived that the willingness of manufacturers to pursue an OBC was a positive sign for the value proposition of the product, while some manufacturers perceived OBCs as particularly valuable negotiation tools to demonstrate the value of their products.

The value for payers of an $\mathrm{OBC}$ was perceived to be driven largely by economic considerations, such as reducing costs, risk, or uncertainty. For manufacturers, the main value drivers were identified as potential access or reimbursement gains (Figure 3).

Importantly, many U.S. payer and manufacturer management executives appear interested in OBCs to showcase value to their customers (e.g., employers and payers, respectively). The staff responsible for contracting expressed more reservation regarding the feasibility of implementation. Feasibility concerns included limited or inappropriate data infrastructure (e.g., lack of relevant/appropriate patient outcomes data); high negotiation complexity (e.g., negotiation may involve numerous stakeholders on the payer and the manufacturer sides, with potential multiple rounds of negotiation in order to finalize the contract); and high internal organizational costs (e.g., as multiple internal stakeholders and resources may be required)

\section{Future OBC Activity and Outlook}

Respondents stated that they expect $\mathrm{OBC}$ activity to increase substantially over the next 5 years (from the time of their interviews; Table 2). In the EU-5, high levels of OBC activity were particularly anticipated in Spain, Italy, Germany, and also potentially in the United Kingdom. Following the introduction of a national OBC framework in 2013, Spain's OBC activity was already underway to match Italy's historical levels (approximately 50 OBCs for the next 5 years). In the United Kingdom, a significant increase in $\mathrm{OBC}$ activity was expected (particularly around new and high-cost products) but will require the introduction of a new OBC framework, which has been expected but delayed by ongoing health care reforms.

In the United States, respondents stated that $\mathrm{OBC}$ activity was expected to increase sharply over the next 5 years (relative to the previous 5 -year period), with an increase in the activity of payers with previous $\mathrm{OBC}$ experience, as well as new OBC arrangements from payers with no previous $\mathrm{OBC}$ experience. Private payers with previous $\mathrm{OBC}$ experience anticipated a more than doubling of their OBCs, from an average of 2.6 previously to $7.4 \mathrm{OBCs}$, and manufacturer participants anticipated about 10 OBCs (on average) over the same period of time.

Most U.S. research participants indicated that emphasis on accountable care will likely further increase longer-term OBC activity. At the same time, while ACO research participants reported that OBCs are aligned conceptually with their goals, it was recognized that ACO models are still evolving and that implementation challenges for these often small organizations will continue to limit $\mathrm{OBC}$ adoption. Limited $\mathrm{OBC}$ activity by CMS was expected over the next 5 years mostly because of the lack of statutory authority and legislative framework.

\section{Discussion}

This research suggests that OBCs are now established and are valuable contracting options for payers and manufacturers in the EU-5 and the United States. The primary research interviews showed that OBC activity has been growing in the EU-5 and the United States over the past 5 years and is expected to continue to increase over the next 5 years. While much of this $\mathrm{OBC}$ activity appears to remain confidential, the targeted literature review of publicized OBCs indicated a positive trend. While some research based on publicized OBC activity suggested a potential slowdown in EU activity after 2011, ${ }^{14,21}$ this review indicates that the slowdown pattern appears to be primarily driven by the noninclusion of AIFA's OBCs during this period.

OBCs are increasingly used by manufacturers and payers in the United States and the EU-5 to address risk associated with certain products and appear to have become an established feature of the market access landscape in the EU-5. 
Particularly in the United States, recent OBC activity indicates that interest in the market has increased significantly. For example, since January 2015, Cigna has publicly disclosed at least 5 OBCs for new products used to treat diabetes, cholesterol, heart failure, and hepatitis C..$^{24,26-28}$ Regional payers and pharmacy benefit managers have also agreed to several OBCs with large manufacturers, including Harvard Pilgrim and Express Scripts. ${ }^{29,30}$ These arrangements seem to provide benefits to payers (national and regional) and manufacturers, particularly for high-cost and/or high-budget products, or to mitigate uncertainty.

Our research on OBCs illustrates some of the growth opportunities and challenges in increasing shared accountability of diverse health care stakeholders while improving patient outcomes. The transition towards health care accountability in the EU-5 and the United States and continued budget pressures are key factors expected to support the trend towards more OBCs. At the same time, OBCs are not a replacement for traditional arrangements, since OBCs may not be appropriate for every product, particularly given costs, complexity, availability of data, or resource requirements. ${ }^{20}$ Similarly, OBCs may not be currently feasible nor desirable for every health care stakeholder (e.g., payer, pharmacy benefit manager, and employer). Consistent with previous literature, we found that significant barriers, such as insufficient data infrastructure and high administrative or initiation burdens, hinder the implementation of OBCs for some health care organizations more than others. ${ }^{31,32}$

The absence of pragmatic frameworks in the United States is a significant hurdle for $\mathrm{OBC}$ growth. Yet, the emergence of widely accepted OBC frameworks can be challenging, particularly given the highly fragmented U.S. health care system. Integrated delivery networks, closed systems with well-established data capabilities (e.g., large private payers), or CMS have a unique opportunity to play a key role in the introduction of such $\mathrm{OBC}$ frameworks.

\section{Limitations}

There some limitations to this research to consider. Interviews were used for the primary research, which are subjective and/or prone to participant selection and recall bias. Further, while the sample of payer and manufacturer participants is larger than other related $\mathrm{OBC}$ research, it reflects a portion of the payer landscape; therefore, the research may not adequately reflect the diverse payer and manufacturer landscape. The interviews and literature review took place from November 2014 to January 2015; therefore, OBC activities that occurred after that time period are not included. Because of the functional perspectives targeted, the diversity of viewpoint across functional areas is also limited. The literature review of publicly disclosed OBCs conducted to complement the PBRS database was targeted and not systematic so may not include all
OBCs publicly disclosed and, in particular, may understate the level of OBC activity publicly disclosed by U.S. regional payers. No PRISMA checklist was used.

\section{Conclusions}

Health care decision makers are increasingly in need of innovative solutions to address health outcome challenges, rising costs, budgetary pressures, and uncertainty. This research suggests that $\mathrm{OBCs}$ are a viable means of addressing some of these concerns and are also a growing alternative to traditional pricing and reimbursement arrangements for some products. Over the next 5 years, our research indicates that $\mathrm{OBC}$ volume is expected to double in the United States as interest accumulates and to increase substantially in the EU-5. The time appears ripe for new $\mathrm{OBC}$ frameworks to be explored and introduced in the United States to support the growing needs of diverse health care stakeholders. Pragmatic frameworks tailored to the U.S. health care landscape need to be established, possibly leveraging knowledge gained from the EU-5 experience.

\section{Authors}

TARA NAZARETH, MPH; JOHN J. KO, PharmD, MS; RAHUL SASANE, PhD; and ASHOK VEGESNA, PharmD, RPh, Novartis Pharmaceuticals, East Hanover, New Jersey. CHRISTIAN FROIS, PhD; STEPHEN CARPENTER, MBA; SEBASTIAN DEMEAN, BA; and ERIC WU, PhD, Analysis Group, Boston, Massachusetts. ROBERT P. NAVARRO, PharmD, University of Florida, Gainesville.

AUTHOR CORRESPONDENCE: Christian Frois, PhD, Analysis Group, 111 Huntington Ave., 14th Fl., Boston, MA 02199.

Tel.: 617.425.8304; E-mail: Christian.Frois@analysisgroup.com.

\section{DISCLOSURES}

This study was funded by Novartis Pharmaceuticals. Novartis employees were involved in all aspects of this study. Vegesna and Sasane are employed by and own stock in Novartis. Nazareth and Ko were employees of Novartis at the time of this study. Frois, Demean, Carpenter, and Wu are or have been employed by Analysis Group, which received a grant from Novartis for this research. Navarro received consulting fees from Novartis for his involvement in this research.

Study concept and design were contributed by Sasane, Frois, Nazareth, and $\mathrm{Wu}$. Navarro, Demean, and Frois took the lead in data collection, assisted by Carpenter, Ko, and Nazareth. Data interpretation was provided by Frois, Carpenter, Nazareth, and Ko, along with Sasane, Demean, Wu, and Navarro. The manuscript was written by Frois, Demean, Nazareth, and Ko, along with Sasane, Carpenter, Wu, and Navarro, and revised by Frois, Ko, and Vegesna, along with Sasane, Nazareth, Wu, and Navarro.

\section{REFERENCES}

1. Coronini-Cronberg S, Bixby H, Laverty AA, Wachter RM, Millett C. English National Health Service's savings plan may have helped reduce the use of three 'low-value' procedures. Health Aff (Millwood). 2015;34(3):381-89. 
2. Giovanella L, Stegmüller K. The financial crisis and health care systems in Europe: universal care under threat? Trends in health sector reforms in Germany, the United Kingdom, and Spain. Cad Saude Publica. 2014;30(11):2263-81.

3. Keckley P, Snyder G. Value-based pricing for pharmaceuticals: implications of the shift from volume to value. Deloitte Center for Health Solutions. Issue brief. 2012. Available at: http://deloitte.wsj.com/cfo/ files/2012/09/ValueBasedPricingPharma.pdf. Accessed August 12, 2017.

4. Latkovic T. The trillion dollar prize: using outcomes-based payment to address the U.S. healthcare financing crisis. McKinsey Report. February 2013. Available at: https://healthcare.mckinsey.com/sites/default/files/thetrillion-dollar-prize.pdf. Accessed August 12, 2017.

5. U.S. Department of Health and Human Resources. Better, smarter, healthier: in historic announcement, HHS sets clear goals and timeline for shifting Medicare reimbursements from volume to value. Press release. January 26, 2015. Available at: https://wayback.archive-it. org/3926/20170127185400/https://www.hhs.gov/about/news/2015/01/26/ better-smarter-healthier-in-historic-announcement-hhs-sets-clear-goals-andtimeline-for-shifting-medicare-reimbursements-from-volume-to-value.html. Accessed August 12, 2017

6. Porter ME, Lee TH. The strategy that will fix health care. Harvard Business Review. 2013;91(10):50-70. Available at: https://hbr.org/2013/10/the-strategythat-will-fix-health-care. Accessed August 12, 2017.

7. Economist Intelligence Unit. Reinventing biopharma: strategies for an evolving marketplace. The innovation imperative in biopharma. White paper. July 11, 2011. Available at: http://www.quintiles.com/library/whitepapers/reinventing-biopharma-strategies-for-an-evolving-marketplace. Accessed August 12, 2017.

8. McKesson Health Solutions. The state of value-based reimbursement and the transition from volume to value in 2014. 2014. Available at: http://mptrms.mckesson.com/rs/MckessonPT/images/ Transitionfromvolumetovaluein2014.pdf. Accessed August 12, 2017.

9. Sussex J, Towse A, Devlin N. Operationalizing value-based pricing of medicines: a taxonomy of approaches. Pharmacoeconomics. 2013;31(1):1-10.

10. Chernew ME, Rosen AB, Fendrick AM. Value-based insurance design. Health Aff (Millwood). 2007;26(2):w195-203.

11. FDANews. CMS seeks to pay less, conduct parallel reviews with FDA. Daily Device Bulletin. April 2, 2011. Available at: http://www.fdanews.com/ articles/105435-cms-seeks-to-pay-less-conduct-parallel-reviews-with-fda. Accessed August 12, 2017

12. Carlson JJ, Garrison LP Jr, Sullivan SD. Paying for outcomes: innovative coverage and reimbursement schemes for pharmaceuticals. J Manag Care Pharm. 2009;15(8):683-87. Available at: http://www.jmcp.org/doi/10.18553/ jmcp.2009.15.8.683.

13. Cook JP, Vernon JA, Manning R. Pharmaceutical risk-sharing agreements. Pharmacoeconomics. 2008;26(7):551-56.

14. Carlson JJ, Gries KS, Yeung K, Sullivan SD, Garrison LP Jr. Current status and trends in performance-based risk-sharing arrangements between healthcare payers and medical product manufacturers. Appl Health Econ Health Policy. 2014;12(3):231-38.

15. Towse A, Garrison L, Puig-Peiró R. The use of pay-for-performance for drugs: can it improve incentives for innovation? Occasional paper 12/01. Office of Health Economics. February 2012. Available at: https://www.ohe. org/publications/use-pay-performance-drugs-can-it-improve-incentivesinnovation. Accessed August 12, 2017.

16. Upton J. Should the U.S. gamble with Risk-Sharing? Pharmaceutical Executive. September 1, 2011. Available at: http://www.pharmexec.com/ should-us-gamble-risk-sharing?rel=canonical. Accessed August 12, 2017.

17. Morgan S, Daw J, Thomson P. International best practices for negotiating 'reimbursement contracts' with price rebates from pharmaceutical companies. Health Aff (Millwood). 2013;32(4):771-77.
18. Vogler S, Zimmermann N, Habl C, Piessnegger J, Bucsics A. Discounts and rebates granted to public payers for medicines in European countries. South Med Rev. 2012;5(1):38-46.

19. Coulton L, Annemans L, Javier J, et al. Risk-sharing schemes worldwide: a landscape analysis of health outcomes-based reimbursement agreements. Poster presented at: ISPOR 4th Asia-Pacific Conference; September 5-7 2010 Phuket, Thailand. Available at: https://www.ispor.org/research_pdfs/35/ pdffiles/PHP15.pdf. Accessed August 12, 2017.

20. Adamski J, Godman B, Ofierska-Sujkowska G, et al. Risk-Sharing arrangements for pharmaceuticals: potential considerations and recommendations for European payers. BMC Health Serv Res. 2010;10:153.

21. Garrison L, Towse A, Neumann P, Carlson J. The next frontier for risksharing agreements in the U.S.: does the changing health care landscape bring new promise for partnerships between manufacturers and payers? Presented at: ISPOR Issues Panel; Montreal, Canada; June 3, 2014. Available at: https://www.ispor.org/meetings/montreal0614/presentations/IP9AllSpeakers.pdf. Accessed August 12, 2017.

22. Garrison L, Carlson J, Bajaj P, et al. Private sector risk-sharing agreements in the United States: trends, barriers, and prospects. Am J Manag Care. 2015;21(9):632-40.

23. Ferrario A, Kanavos P. Managed entry agreements for pharmaceuticals: the European experience. Discussion paper. EMiNet. 2013. Brussels, Belgium. Available at: http://core.ac.uk/download/pdf/16379320.pdf. Accessed August 12, 2017.

24. Cigna. CIGNA and Merck sign performance-based contract. Business Wire. April 23, 2009. Available at: http://www.businesswire.com/news/ home/20090423005503/en/CIGNA-Merck-Sign-Performance-BasedContract. Accessed August 12, 2017.

25. University of Washington School of Pharmacy. Performance Based Risk Sharing Database (PBRS). 2014. Available at: https://depts.washington.edu/ pbrs/index.php. Accessed August 24, 2017.

26. Cigna. Cigna's two new value-based contracts with pharma for PCSK9 inhibitor cholesterol drugs tie financial terms to improved customer health. News release. May 11, 2016. Available at: https://www.cigna.com/newsroom/ news-releases/2016/cignas-two-new-value-based-contracts-with-pharma-forpcsk9-inhibitor-cholesterol-drugs-tie-financial-terms-to-improved-customer-health. Accessed August 12, 2017.

27. Cigna. Cigna implements value-based contract with Novartis for heart drug Entresto. News release. February 8, 2016. Available at: https://www. cigna.com/newsroom/news-releases/2016/cigna-implements-value-basedcontract-with-novartis-for-heart-drug-entrestotm. Accessed August 12, 2017.

28. Cigna. Cigna signs agreement with Gilead to improve affordability of hepatitis $C$ treatment for customers and clients. News release. February 4 , 2015. Available at: https://www.cigna.com/newsroom/news-releases/2015/ cigna-signs-agreement-with-gilead-to-improve-affordability-of-hepatitis-ctreatment-for-customers-and-clients. Accessed August 12, 2017.

29. Amgen. Amgen and Harvard Pilgrim agree to first cardiovascular outcomes-based refund contract for Repatha (evolocumab). News release. May 2, 2017. Available at: https://www.amgen.com/media/news-releases/2017/05/ amgen-and-harvard-pilgrim-agree-to-first-cardiovascular-outcomesbasedrefund-contract-for-repatha-evolocumab/. Accessed August 12, 2017.

30. Loftus P, Mathews AW. Health insurers push to tie drug prices to outcomes. The Wall Street Journal. May 11, 2016. Available at: https:// www.wsj.com/articles/health-insurers-push-to-tie-drug-prices-to-outcomes-1462939262. Accessed August 12, 2017.

31. Neumann PJ, Chambers JD, Simon F, Meckley LM. Risk-sharing arrangements that link payment for drugs to health outcomes are proving hard to implement. Health Aff (Millwood). 2011;30(12):2329-37.

32. Carlson J, Sullivan SD, Garrison LP, Neumann PJ, Veenstra DL. Linking payment to health outcomes: a taxonomy and examination of performancebased reimbursement schemes between healthcare payers and manufacturers. Health Policy. 2010;96(3):179-90. 